\title{
Physiological responses of Pterocladia and Gelidium (Gelidiales, Rhodophyta) from the Azores, Portugal
}

\author{
Richard A. Fralick ${ }^{1}$, H. P. Baldwin ${ }^{2}$, A. I. Neto ${ }^{3}$ \& E. J. Hehre ${ }^{2}$ \\ ${ }^{1}$ Natural Science Dept., Plymouth State College of the University System of New Hampshire, Plymouth, \\ NH 03264, USA; ${ }^{2}$ Dept. of Botany and Plant Pathology, University of New Hampshire, Plymouth, NH \\ 03824, USA; ${ }^{3}$ Dept. of Biology, University of the Azores, Rua Mae de Deus, Ponta Delgada, Sao Miguel, \\ Azores, Portugal
}

Key words: Gelidium, photosynthesis, physiological responses, Pterocladia, Rhodophyta

\begin{abstract}
Manometric studies were conducted on Pterocladia capillacea, Gelidium latifolium and Gelidium spinulosum from the Azores, Portugal to determine optimal values of temperature, light and salinity for growth. Physiological responses were considered in relation to vertical distribution patterns of these species commonly observed throughout the Azores. Optimal parameters for the growth of Pterocladia capillacea, Gelidium latifolium and G. spinulosum were 17 to $25^{\circ} \mathrm{C}$, a photon flux density between 200 and $300 \mu \mathrm{mol}$ $\mathrm{m}^{-2} \mathrm{~s}^{-1}$ and salinities of 25 to $35 \%$.
\end{abstract}

\section{Introduction}

Numerous authors have studied the geographic and vertical distribution of the Gelidiales. Much of this work has been summarized by Santelices (1974); however, literature is lacking in information on the physiological-ecology of gelidioid species from the Azores, Portugal. Two of three species of Gelidium and one species of Pterocladia were included in this study: Gelidium spinulosum (Agardh) J. Agardh, Gelidium latifolium (Grev.) Bornet et Thuret and Pterocladia capillacea (S. Gmelin) Bornet et Thuret. Each of the species occupies a different vertical niche with only minimal overlap occurring between $G$. latifolium and $P$. capillacea (Fig. 1).

Several reasons combine to make this project of interest. First, there are few published data to account for intertidal benthic macroalgal distributions in the Azores; second, there is potential economic value in these species for two existing

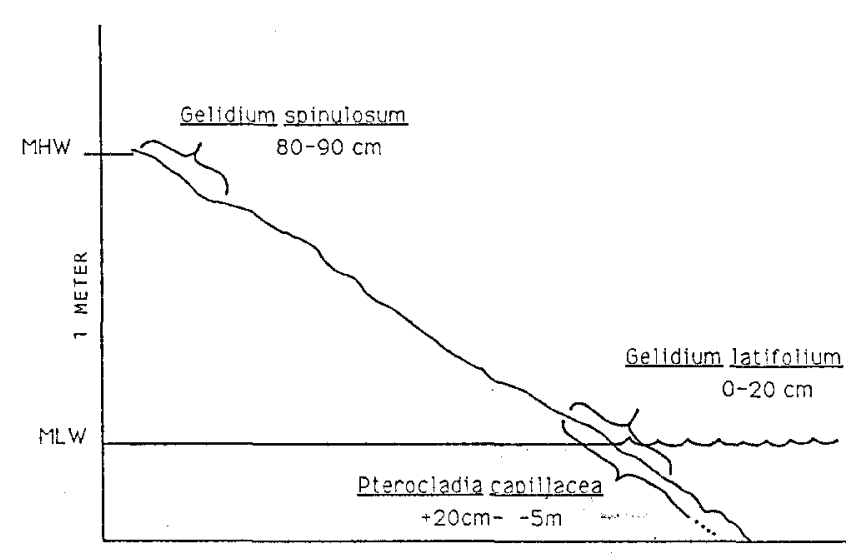

Fig. 1. Zonation profile for Pterocladia and Gelidium spp. from the Azores, Portugal.

agar-producing plants, and third, there is a need to determine optimal growth parameters for these species in anticipation of a proposed aquaculture pilot study. Harvesting impacts of Azores Pterocladia over the past decade have created a need 
for additional knowledge of gelidioid species in the area, which are required to sustain a declining industry.

Pterocladia capillacea is the sole source of raw material for the agar factories. Another species, Gelidium spinulosum, referred to locally as 'Cabalhão' has reportedly been used to improve the gel strength of agar-agar extracted from Pterocladia. Our personal observations on the islands of Terceira and São Miguel indicate that small amounts of G. spinulosum are collected, dried, kept separate from Pterocladia collections and when necessary used specifically for this gel-. enhancing purpose.

The purpose of this work was to obtain a fundamental understanding of the optimal physiological parameters for growth of Azores gelidioid algae. In addition, we were interested in their physiological tolerances to temperature changes in relation to their intertidal distribution patterns.

\section{Materials and methods}

Specimens of Pterocladia and Gelidium were collected in the intertidal zone of the Island of Faial, Azores, Portugal during June, 1988. Additional material was collected on the island of São Miguel, Azores in January, 1989. Specimens were placed in a cooler with ice and transported within $12 \mathrm{~h}$ to Plymouth, New Hampshire, USA and stored under conditions of $10: 14$ (LD) at $84 \mu \mathrm{mol} \mathrm{m} \mathrm{m}^{-2} \mathrm{~s}^{-1}$ and $10^{\circ} \mathrm{C}$. The thalli were maintained in a culture media made from UV filtered seawater enriched with alga-grow nutrient concentrate from Carolina Biological Supply Co. The media was changed every 10 days throughout the study. Apparent photosynthesis rates were recorded in a Gilson Differential Respirometer equipped with a series of 50 Watt incandescent light bulbs. Light intensities (Fig. 2) were varied using a rheostat and were measured with a LI-COR (Li 185 B) Quantum/Radiometer/ Photometer. Respiration experiments were undertaken in a darkened room. All fronds were equilibrated for a minimum of $30 \mathrm{~min}$ prior to each

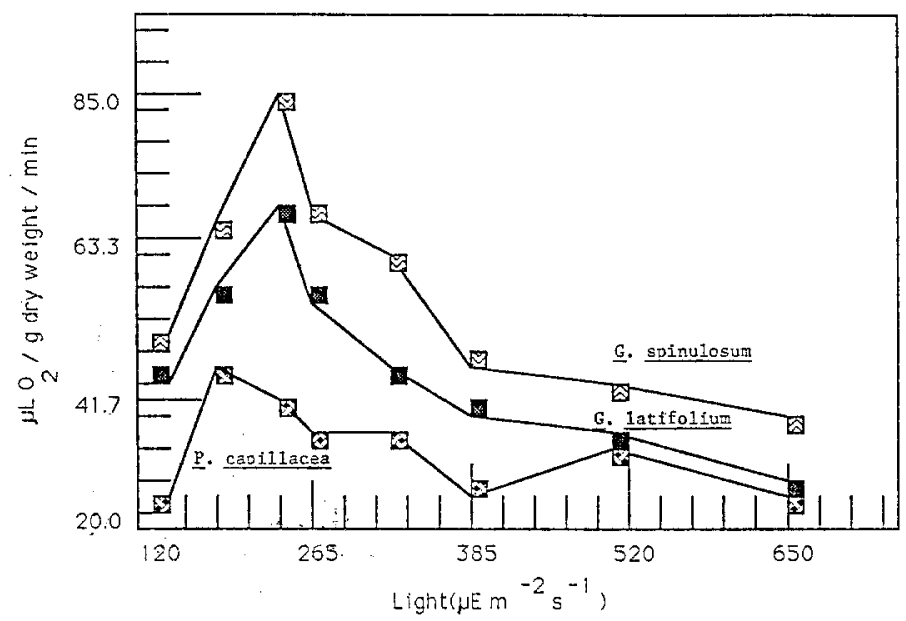

Fig. 2. Apparent photosynthesis for Pterocladia and Gelidium spp. at different light intensities.

trial; each experiment had 10 replicates. In general, the methodology for these experiments followed those of Fralick \& Mathieson (1975), Dawes (1981) and Mathieson \& Dawes (1986).

\section{Results}

\section{Photosynthesis and light}

Optimal photosynthesis for Pterocladia capillacea occurred at $177 \mu \mathrm{mol} \mathrm{m}{ }^{-2} \mathrm{~s}^{-1}$ and for Gelidium spinulosum and $G$. latifolium at $225 \mu \mathrm{mol} \mathrm{m}^{-2} \mathrm{~s}^{-1}$ (Fig. 2). Oxygen production values for $P$. capillacea remained high up to $320 \mu \mathrm{mol}$, but were minimal at light levels of $125 \mu \mathrm{mol}$ and beyond $385 \mu \mathrm{mol}$. The optimal ranges for $G$. spinulosum and $G$. latifolium were similar with higher values occurring between $250 \mu \mathrm{mol}$ and $385 \mu \mathrm{mol}$. Minimal ranges for oxygen production for both Gelidium species occurred at $120 \mu \mathrm{mol}$.

\section{Photosynthesis and temperature}

Minimal oxygen evolution values were recorded for all species at temperatures below $10^{\circ} \mathrm{C}$ (Fig. 3). Optimal values for Pterocladia capillacea were recorded between 15 and $25^{\circ} \mathrm{C}$. Beyond this $P$. capillacea showed some degree of tempera- 


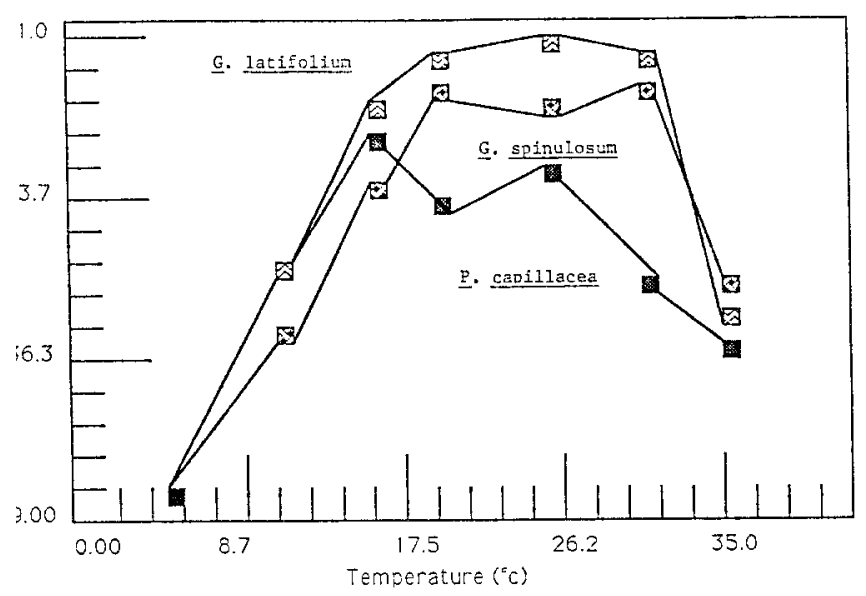

Fig. 3. Apparent photosynthesis of Pterocladia and Gelidium spp. at different temperatures.

ture tolerance up to about $30^{\circ} \mathrm{C}$, but the values declined substantially at that point.

Apparent photosynthesis for Gelidium spinulosum increased in a linear manner from 5 to $15^{\circ} \mathrm{C}$. Optimal values were exhibited between 15 and $30^{\circ} \mathrm{C}$. Gelidium latifolium values also increased in a linear manner from 5 to $15^{\circ} \mathrm{C}$ and remained constant to $30^{\circ} \mathrm{C}$. The rates of photosynthesis declined beyond $30^{\circ} \mathrm{C}$ for these species.

\section{Photosynthesis and salinity}

Apparent photosynthesis for Pterocladia capillacea, Gelidium spinulosum and G. latifolium along

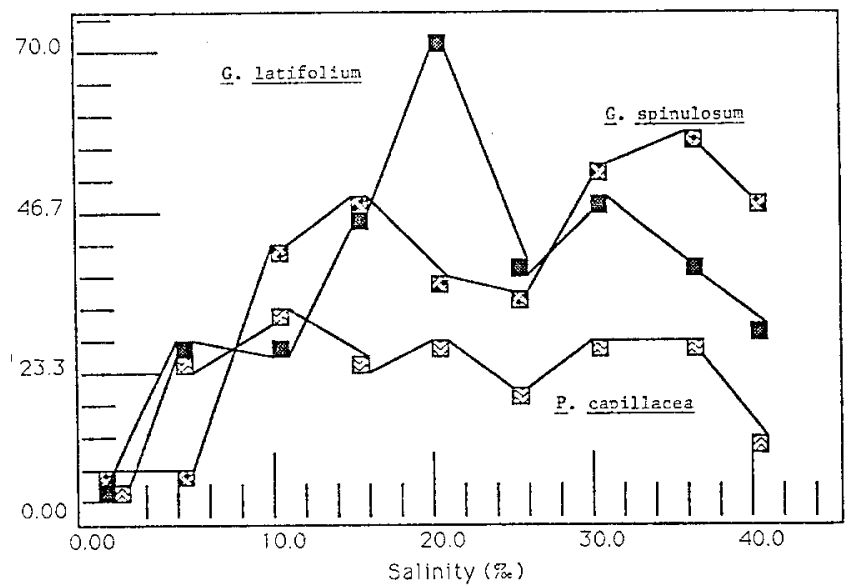

Fig. 4. Apparent photosynthesis of Pterocladia and Gelidium spp. at different salinities.

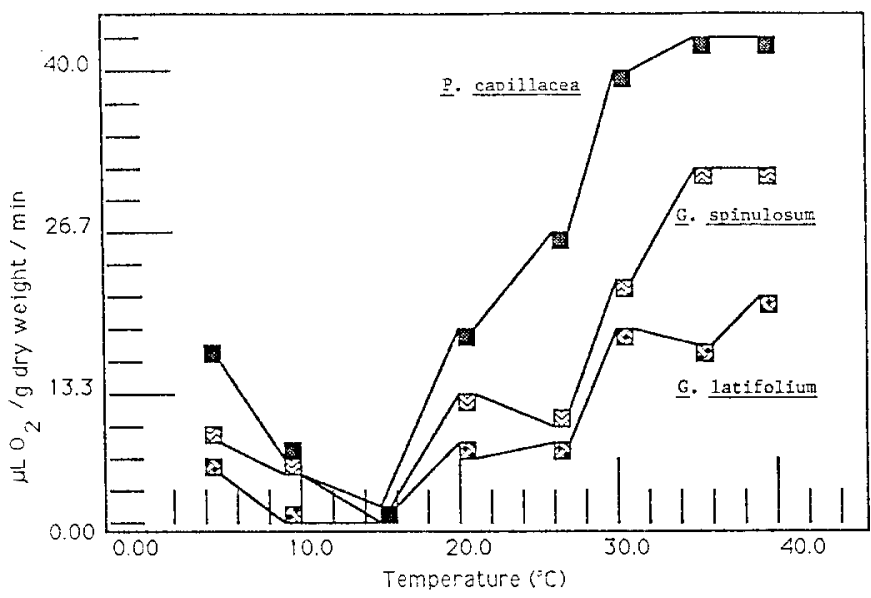

Fig. 5. Respiration values for Pterocladia and Gelidium spp. at different temperatures.

a salinity gradient at $15^{\circ} \mathrm{C}$ is seen in Fig. 4. The values were nearly constant for each of the species at salinities of $15 \%$ and greater with the exception of G. latifolium, which showed an unusual increase at $20 \%$. A slight increase in optimal salinity at $35 \%$ was observed for G. spinulosum.

\section{Respiration and temperature}

Respiration values for Pterocladia capillacea, Gelidium spinulosum and G. latifolium at different temperatures are shown in Fig. 5. The lowest values for all three species occurred at $15^{\circ} \mathrm{C}$. The rate of respiration for $P$. capillacea increased rapidly at temperatures above $15^{\circ} \mathrm{C}$ and continued to increase up to $30^{\circ} \mathrm{C}$ but remained steady beyond this temperature. The rate of increase in respiration differed for the two Gelidium species with increases continuing up to $30{ }^{\circ} \mathrm{C}$ and then also remaining steady from 35 to $40^{\circ} \mathrm{C}$ for $G$. spinulosum.

\section{Discussion}

Photosynthesis was reduced at temperatures above $25^{\circ} \mathrm{C}$ and $30^{\circ} \mathrm{C}$ for Pterocladia and both Gelidium species, respectively. This suggests that temperatures above $25^{\circ} \mathrm{C}$ may stress Pterocladia plants and restrict their distribution in the upper 
intertidal zone. Tolerance to temperatures from $25^{\circ} \mathrm{C}$ to $30^{\circ} \mathrm{C}$ for both Gelidium species may provide the plants with a means for survival in both the upper intertidal for $G$. spinulosum and in the lower intertidal for $G$. latifolium.

Respiration rates show a lower temperature tolerance for Pterocladia and a slightly higher tolerance for both Gelidium species. Minimal respiratory stress for all three species occurred at $15^{\circ} \mathrm{C}$. No stress-related values were recorded for Pterocladia or Gelidium at salinities below $15 \%$. However, all species showed a slight decrease in photosynthesis at salinities of $40 \%$.

Temperature may be a significant factor among others influencing the vertical distribution of $P$. capillacea, G. latifolium and $G$. spinulosum in the intertidal zone of the Azores. However, more long-term field data is necessary to clearly understand the influence of other variables on vertical distribution. Such variables as herbivory, temperature and porosity of the substratum, exposure to sunlight and high energy wave action should be considered on a seasonal basis and compared with manometric results to clarify intertidal algal stratification.

\section{Acknowledgements}

This work was supported by a faculty development grant from Plymouth State College and by the Biology Department of the University of the Azores. We also acknowledge the assistance, from Dean Theodora Kalikow, April O'Keefe and Chris Boland.

\section{References}

Dawes, C. J., 1981. Marine Botany. Wiley-Interscience, New York, USA, 628 pp.

Fralick, R. A. \& A. C. Mathieson, 1975. Physiological ecology of four Polysiphonia species (Rhodophyta, Ceramiales). Mar. Biol. 29: 29-36.

Mathieson, A. C. \& C. J. Dawes, 1986. Photosynthetic response of Florida seaweeds to light and temperature: physiological survey. Bull. mar. Sci. 38:-512-514.

Santelices, B., 1974. Gelidioid algae, a brief resume of the pertinent literature. Tech. Rpt. No. 1 U.S. Sea Grant Program, University of Hawaii, $111 \mathrm{pp}$. 